\title{
THE ROLE OF METHODOLGY IN PEDAGOGICAL RESEARCH IN TERMS OF IMPROVING SKILLS OF HIGH SCHOOL STUDENTS PROGRAMMING
}

Linda Jurakovic

PhD in Law, Assistant Professor, Juraj Dobrila University of Pula,

30 Zagrebačka, Pula, Croatia, 52100

linda.jurakovic@unipu.hr

Marina Vekić

mag.educ.inf., Juraj Dobrila University of Pula,

30 Zagrebačka, Pula, Croatia, 52100

vekic.marina052@gmail.com

Monika Marković

mag.educ.inf., Juraj Dobrila University of Pula,

30 Zagrebačka, Pula, Croatia, 52100

monika.markovic2@skole.hr

\begin{abstract}
This paper presents analysis of learning and programming skills of students in High School, course computer technician. Students from all grades participated in the research. In this research the attitudes of students were examined for subject "Algorithms and programming". Also, research includes programming skills that were tested using specific test. Based on the obtained data, detailed analysis was performed. This analysis includes comparison of programming skills and knowledge between grades in school, comparison of attitudes related to subject and comparison of student's average grade with results on the given test. Based on the results obtained, proposals for improving the skills of programming are given.
\end{abstract}

Keywords: programming, programming languages, algorithms and data structures, programming skills, computer technician.

\section{INTRODUCTION}

Programming is not just about writing program codes but it is a complex process that requires a number of skills. For the development of computer programs, the programmer must be able to solve problems, spot and eliminate errors, have developed abstract, logical and computer thinking and the ability to analyze. Teachers who teach programming try to 
find the best methods to make it easier for students to master the material. They are often in a dilemma when choosing teaching methods and forms of teaching, since there is no single guide for teaching programming. In most schools, programming is taught in a traditional way consisting of lessons, homework and demonstration assignments. However, the teacher should strive to teach students how to combine parts of the program code into a meaningful whole. Research has shown that learning programming from an early age has positive effects on students 'day-to-day development. In this way, students develop logical thinking and reasoning that they can apply to all spheres of life. Students in the beginnings of learning programming most often use programming languages and tools that are visually reminiscent of a game or puzzle. Such languages are suitable for younger students because they do not give the impression of seriousness.

The aim of this research is to gain insight into the current state of programming skills of high school students, majoring in computer technician in order to improve the quality and more meaningful implementation of programming classes. In accordance with the set goal of the research and the Vocational Curriculum for the qualification of computer technician, the basic educational categories of programming skills are defined: basic data types, variables and constants, branching commands, program loops, one-dimensional fields, functions, sorting algorithms and data structures. The research sought an answer to the question of whether high school students, computer technicians, have developed programming skills in accordance with the set curriculum outcomes and whether there is a significant difference in knowledge and programming skills among lower and upper grade students. Given that programming is one of the key skills of the future, this topic is becoming increasingly relevant. Namely, the Ministry of Science and Education in cooperation with the Agency for Vocational Education and Training in 2019 conducted national exams in vocational education aimed at determining the level of knowledge and skills of students in vocational subjects, which speaks of the importance of this issue.

\section{MATERIALS AND METHODS}

The research on the topic "The role of pedagogical research methodology in order to increase the programming skills of high school students" was conducted in the period from 20 to 24 May 2019. This period was chosen because until then, first-graders had mostly processed all first-grade material, which is important for conducting testing because the research is based on programming knowledge, ie the subject "Algorithms and Data Structures". The survey questionnaire consists of three parts. The first part refers to general data about the respondent, the second part about the attitudes of the respondents for the subject "Algorithms and Programming" and the third part in which the programming skills in the $\mathrm{C}++$ programming language are assessed. The estimated time for solving the questionnaire was 40 minutes. Qualitative and quantitative data processing was performed on the collected data.

The following hypotheses are set: 
H0: Developed programming skills of high school students, majoring in computer technician, are not in line with the set outcomes of the Vocational Curriculum for acquiring the qualification of computer technician for the subject "Algorithms and Programming".

H1: There is no significant difference in programming knowledge and skills between lower (first, second, third grade) students and fourth grade high school students.

H2: Students with poorer general averages have less developed programming skills.

H3: Students who have a negative attitude about the subject "Algorithms and Programming" have less developed programming skills.

The study population consisted of 78 subjects $(\mathrm{N}=78)$. In the first and second grade, 22 students were examined, in the third 18, and in the fourth 16 students. The distribution of respondents by grades is shown in Graph 1.

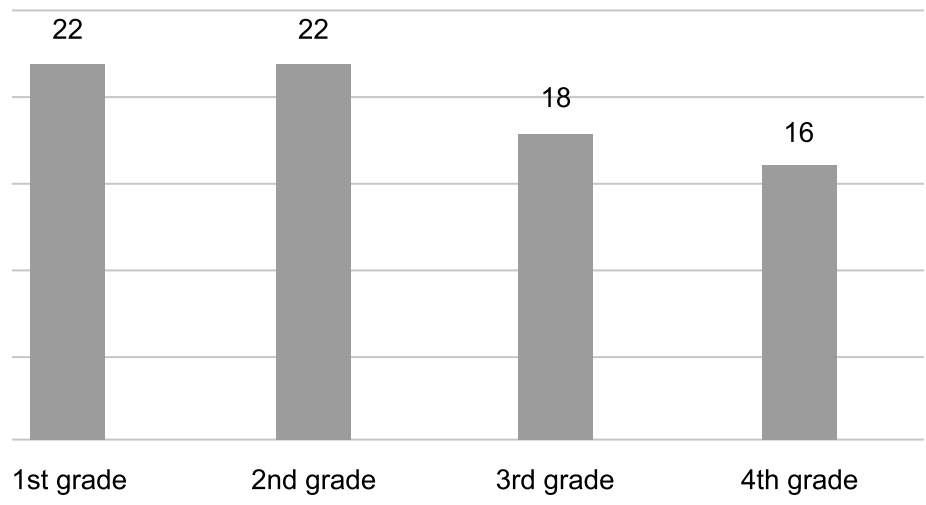

Graph 1 shows the distribution of respondents by grades

Source: prepared by the author according to the conducted research

First grade and second grade accounted for $28.21 \%$ of the total number of respondents. The third grade accounted for $23.08 \%$ and the fourth for $20.51 \%$ of the total number of respondents. Out of a total of 78 respondents, 6 and $7.69 \%$ of girls and 72 and $92.31 \%$ of boys, respectively, participated in the research. This ratio of girls and boys is justified by the fact that in our society there is still a small representation of women in the technical sciences.

Based on the survey data, the average grade at the end of the previous grade for the first grade is 3.73 , for the second 3.18 , the average grade of the third grade is 3.50 , and the fourth 3.44 as shown in Graph 2 (Croatian grading system).

\section{Average grade of students from each class in the previous class}

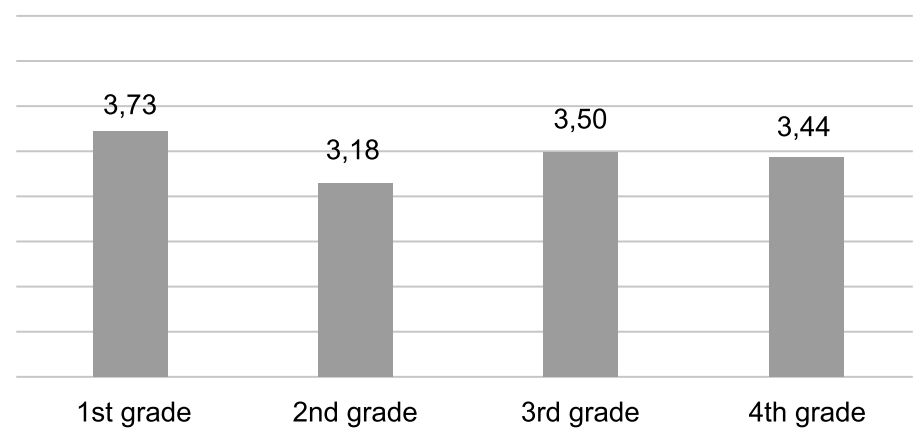

Graph 2 Average grade of students from each class in the previous class Source: prepared by the author according to the conducted research 
In the second part of the questionnaire, respondents were asked to state their position regarding the subject "Algorithms and Programming".

For the first statement "At the beginning of classes, interest in the contents of the case was great" out of 78 respondents, $5(6.41 \%)$ answered that they completely disagree, 9 respondents (11.54\%) said that they did not agree with statement, 16 respondents $(20.51 \%)$ neither agree nor disagree with the statement, 25 respondents $(32.05 \%)$ agree with the statement, 20 respondents (25.64\%) fully agree with the statement, while 3 respondents $(3.85 \%)$ cannot give an estimate for the stated claim.

Statistics
\begin{tabular}{|l|r|}
\hline Nvrdnja1 & Valid \\
\multicolumn{1}{|c|}{ Missing } & 78 \\
Mean & 0 \\
Median & 3,4744 \\
Mode & 4,0000 \\
Std. Deviation & 1,36491 \\
\hline
\end{tabular}

\begin{tabular}{|ll|r|r|r|r|}
\multicolumn{7}{|c|}{ Tvrdnja1 } \\
\hline & & Frequency & Percent & $\begin{array}{c}\text { Valid } \\
\text { Percent }\end{array}$ & $\begin{array}{c}\text { Cumulative } \\
\text { Percent }\end{array}$ \\
\hline Valid &, 00 & 3 & 3,8 & 3,8 & 3,8 \\
& 1,00 & 5 & 6,4 & 6,4 & 10,3 \\
& 2,00 & 9 & 11,5 & 11,5 & 21,8 \\
& 3,00 & 16 & 20,5 & 20,5 & 42,3 \\
& 4,00 & 25 & 32,1 & 32,1 & 74,4 \\
& 5,00 & 20 & 25,6 & 25,6 & 100,0 \\
& Total & 78 & 100,0 & 100,0 & \\
\hline
\end{tabular}

Figure 1 shows the statistical analysis of the 1 st statement Source: prepared by the author according to the conducted research

To the second statement "The goals and tasks of the case were clearly defined" out of 78 respondents, 2 of them (2.56\%) answered that they completely disagree, 4 respondents $(5.13 \%)$ said that they did not agree with the statement, 20 respondents $(25.64 \%)$ neither agree nor disagree with the statement, 30 respondents $(38.46 \%)$ agree with the statement, 21 respondents (26.92\%) fully agree with the statement, while 1 respondent $1.28 \%$ ) cannot give an estimate for the stated claim.

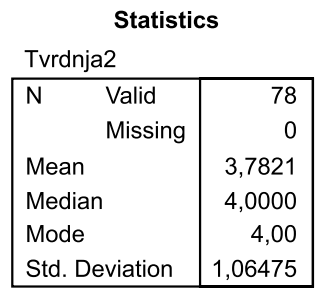

\begin{tabular}{|c|c|c|c|c|c|}
\hline \multicolumn{6}{|c|}{ Tvrdnja2 } \\
\hline & & Frequency & Percent & $\begin{array}{c}\text { Valid } \\
\text { Percent }\end{array}$ & $\begin{array}{c}\text { Cumulative } \\
\text { Percent }\end{array}$ \\
\hline \multirow[t]{7}{*}{ Valid } & ,00 & 1 & 1,3 & 1,3 & 1,3 \\
\hline & 1,00 & 2 & 2,6 & 2,6 & 3,8 \\
\hline & 2,00 & 4 & 5,1 & 5,1 & 9,0 \\
\hline & 3,00 & 20 & 25,6 & 25,6 & 34,6 \\
\hline & 4,00 & 30 & 38,5 & 38,5 & 73,1 \\
\hline & 5,00 & 21 & 26,9 & 26,9 & 100,0 \\
\hline & Total & 78 & 100,0 & 100,0 & \\
\hline
\end{tabular}

Figure 2 shows the statistical analysis of the 2 nd statement

Source: prepared by the author according to the conducted research 
For the third statement "Organization of teaching encouraged me to actively participate in teaching" out of 78 respondents 6 of them (7.69\%) answered that they completely disagree, 3 respondents (3.85\%) said that they do not agree with the statement , 31 respondents $(39.74 \%)$ neither agree nor disagree with the statement, 25 respondents $(32.05 \%)$ agree with the statement, 12 respondents (15.38\%) fully agree with the statement, while 1 respondent (1.28\%) cannot give an estimate for the stated claim.

\begin{tabular}{|c|c|c|c|c|c|}
\hline & Statis & tics & & & \\
\hline Tvrdnj & & & & & \\
\hline $\mathrm{N}$ & Valid & 78 & & & \\
\hline & Missing & 0 & & & \\
\hline Mean & & 3,3974 & & & \\
\hline Media & & 3,0000 & & & \\
\hline Mode & & 3,00 & & & \\
\hline Std. D & eviation & 1,12053 & & & \\
\hline & & & Tvrdnja & & \\
\hline & & Frequency & Percent & $\begin{array}{c}\text { Valid } \\
\text { Percent }\end{array}$ & $\begin{array}{c}\text { Cumulative } \\
\text { Percent }\end{array}$ \\
\hline Valid & ,00 & 1 & 1,3 & 1,3 & 1,3 \\
\hline & 1,00 & 6 & 7,7 & 7,7 & 9,0 \\
\hline & 2,00 & 3 & 3,8 & 3,8 & 12,8 \\
\hline & 3,00 & 31 & 39,7 & 39,7 & 52,6 \\
\hline & 4,00 & 25 & 32,1 & 32,1 & 84,6 \\
\hline & 5,00 & 12 & 15,4 & 15,4 & 100,0 \\
\hline & Total & 78 & 100,0 & 100,0 & \\
\hline
\end{tabular}

Figure 3 shows the statistical analysis of the 3 rd statement

Source: prepared by the author according to the conducted research

To the fourth statement "Teaching materials were understandable and accessible" out of 78 respondents, none of the respondents answered that they completely agree, 6 respondents $(7.69 \%)$ said that they did not agree with the statement, 17 respondents neither agree nor disagree with the statement, 25 respondents (32.05\%) agree with the statement, 29 respondents (37.18\%) fully agree with the statement, while 1 respondent $(1.28 \%)$ cannot give an estimate for the above statement.

Statistics
\begin{tabular}{|l|r|}
\hline Nvrdnja4 & Valid \\
\multicolumn{1}{|c|}{ Missing } & 78 \\
Mean & 0 \\
Median & 3,9487 \\
Mode & 4,0000 \\
Std. Deviation & 1,05557 \\
\hline
\end{tabular}

\begin{tabular}{|ll|r|r|r|r|}
\multicolumn{7}{|c|}{ Tvrdnja4 } \\
\hline & & Frequency & Percent & $\begin{array}{c}\text { Valid } \\
\text { Percent }\end{array}$ & $\begin{array}{c}\text { Cumulative } \\
\text { Percent }\end{array}$ \\
\hline Valid &, 00 & 1 & 1,3 & 1,3 & 1,3 \\
& 2,00 & 6 & 7,7 & 7,7 & 9,0 \\
& 3,00 & 17 & 21,8 & 21,8 & 30,8 \\
4,00 & 25 & 32,1 & 32,1 & 62,8 \\
& 5,00 & 29 & 37,2 & 37,2 & 100,0 \\
& Total & 78 & 100,0 & 100,0 & \\
\hline
\end{tabular}

Figure 4 shows the statistical analysis of the 4 th statement Source: prepared by the author according to the conducted research 
For the fifth statement "I think that the teaching content enables the development of skills and practical application of knowledge" out of 78 respondents, none of the respondents answered that they completely disagree, 6 respondents (7.69\%) said that they did not agree with the statement, 16 respondents (20.51\%) neither agree nor disagree with the statement, 35 respondents (44.87\%) agree with the statement, 19 respondents (24.36\%) fully agree with the statement, while 2 respondents $(2,56 \%)$ cannot give an estimate for the stated claim.

Statistics
\begin{tabular}{|l|r|}
\hline Tvrdnja5 \\
\hline \multicolumn{1}{|c|}{ Valid } & Missing \\
Mean & 0 \\
Median & 3,7821 \\
Mode & 4,0000 \\
Std. Deviation & 4,05475 \\
\hline
\end{tabular}

\begin{tabular}{|rl|r|r|r|r|}
\multicolumn{7}{|c|}{ Tvrdnja5 } \\
\hline & & Frequency & Percent & $\begin{array}{c}\text { Valid } \\
\text { Percent }\end{array}$ & $\begin{array}{c}\text { Cumulative } \\
\text { Percent }\end{array}$ \\
\hline Valid &, 00 & 2 & 2,6 & 2,6 & 2,6 \\
& 2,00 & 6 & 7,7 & 7,7 & 10,3 \\
& 3,00 & 16 & 20,5 & 20,5 & 30,8 \\
& 4,00 & 35 & 44,9 & 44,9 & 75,6 \\
& 5,00 & 19 & 24,4 & 24,4 & 100,0 \\
& Total & 78 & 100,0 & 100,0 & \\
\hline
\end{tabular}

Figure 5 shows the statistical analysis of the 5 th statement

Source: prepared by the author according to the conducted research

To the sixth statement "Knowledge from this subject helped me to master other professional subjects" out of 78 respondents, 20 of them (25.64\%) answered that they completely disagree, 10 respondents (12.82\%) said that disagrees with the statement, 21 respondents $(26.92 \%)$ neither agree nor disagree with the statement, 13 respondents $(16.67 \%)$ agree with the statement, 10 respondents (12.82\%) fully agree with the statement, while 4 respondents (5.13\%) cannot give an estimate for the stated claim.

Statistics
\begin{tabular}{|lr|r|}
\hline Tvrdnja6 \\
\hline \multicolumn{1}{|c|}{ Valid } & Missing & 0 \\
Mean & 2,6282 \\
Median & 3,0000 \\
Mode & 3,00 \\
Std. Deviation & 1,47806 \\
\hline
\end{tabular}

\begin{tabular}{|c|c|c|c|c|c|}
\hline \multicolumn{6}{|c|}{ Tvrdnja6 } \\
\hline & & Frequency & Percent & $\begin{array}{c}\text { Valid } \\
\text { Percent }\end{array}$ & $\begin{array}{c}\text { Cumulative } \\
\text { Percent }\end{array}$ \\
\hline \multirow[t]{7}{*}{ Valid } & ,00 & 4 & 5,1 & 5,1 & 5,1 \\
\hline & 1,00 & 20 & 25,6 & 25,6 & 30,8 \\
\hline & 2,00 & 10 & 12,8 & 12,8 & 43,6 \\
\hline & 3,00 & 21 & 26,9 & 26,9 & 70,5 \\
\hline & 4,00 & 13 & 16,7 & 16,7 & 87,2 \\
\hline & 5,00 & 10 & 12,8 & 12,8 & 100,0 \\
\hline & Total & 78 & 100,0 & 100,0 & \\
\hline
\end{tabular}

Figure 6 shows the statistical analysis of the 6 th statement

Source: prepared by the author according to the conducted research 
For the seventh statement "The teacher presented the content in an understandable way and was available for additional questions and explanations" out of 78 respondents, 3 of them (3.85\%) answered that they completely disagree, 4 respondents (5.13\%) said they did not agree with the statement, 12 respondents (15.38\%) neither agree nor disagree with the statement, 19 respondents (24.36\%) agreed with the statement, 40 respondents (51.28\%) fully agrees with the claim.

Statistics
\begin{tabular}{|lr|r|}
\hline Tvrdnja7 \\
\hline \multicolumn{1}{|c|}{ Valid } & Missing & \\
Mean & 0 \\
Median & 5,1410 \\
Mode & 5,0000 \\
Std. Deviation & 5,00 \\
& 1,10164 \\
\hline
\end{tabular}

\begin{tabular}{|rr|r|r|r|r|}
\multicolumn{7}{c|}{ Tvrdnja7 } \\
\hline & & Frequency & Percent & $\begin{array}{c}\text { Valid } \\
\text { Percent }\end{array}$ & $\begin{array}{c}\text { Cumulative } \\
\text { Percent }\end{array}$ \\
\hline Valid & 1,00 & 3 & 3,8 & 3,8 & 3,8 \\
& 2,00 & 4 & 5,1 & 5,1 & 9,0 \\
& 3,00 & 12 & 15,4 & 15,4 & 24,4 \\
& 4,00 & 19 & 24,4 & 24,4 & 48,7 \\
& 5,00 & 40 & 51,3 & 51,3 & 100,0 \\
& Total & 78 & 100,0 & 100,0 & \\
\hline
\end{tabular}

Figure 7 shows the statistical analysis of the 7 th statement Source: prepared by the author according to the conducted research

To the eighth statement "The contents of this case increased my interest in programming" out of 78 respondents, 12 (15.38\%) answered that they completely disagree, 15 respondents (19.23\%) said they did not agree with , 19 respondents (24.36\%) neither agree nor disagree with the statement, 18 respondents (23.08\%) agree with the statement, 13 respondents (16.67\%) fully agree with the statement, while 1 respondent $(1.28 \%)$ cannot give an estimate for the stated claim.

Statistics
\begin{tabular}{|lr|r|}
\hline Tvrdnja8 & Valid & 78 \\
& Missing & 0 \\
Mean & 3,0256 \\
Median & 3,0000 \\
Mode & 3,00 \\
Std. Deviation & 1,35775 \\
\hline
\end{tabular}

\begin{tabular}{|c|c|c|c|c|c|}
\hline \multicolumn{6}{|c|}{ Tvrdnja8 } \\
\hline & & Frequency & Percent & $\begin{array}{c}\text { Valid } \\
\text { Percent }\end{array}$ & $\begin{array}{c}\text { Cumulative } \\
\text { Percent }\end{array}$ \\
\hline Valid &, 00 & 1 & 1,3 & 1,3 & 1,3 \\
\hline & 1,00 & 12 & 15,4 & 15,4 & 16,7 \\
\hline & 2,00 & 15 & 19,2 & 19,2 & 35,9 \\
\hline & 3,00 & 19 & 24,4 & 24,4 & 60,3 \\
\hline & 4,00 & 18 & 23,1 & 23,1 & 83,3 \\
\hline & 5,00 & 13 & 16,7 & 16,7 & 100,0 \\
\hline & Total & 78 & 100,0 & 100,0 & \\
\hline
\end{tabular}

Figure 8 shows the statistical analysis of the 8th statement Source: prepared by the author according to the conducted research

For the ninth statement "I mastered the teaching content with difficulty" out of 78 respondents, 15 (19.23\%) answered that they completely disagree, 21 respondents 
$(26.92 \%)$ said that they did not agree with the statement, 15 respondents $(19.23 \%)$ neither agree nor disagree with the statement, 13 respondents (16.67\%) agree with the statement, 11 respondents (14.10\%) fully agree with the statement, while 3 respondents $3.85 \%$ ) cannot give an estimate for the stated claim.

Statistics
\begin{tabular}{|l|r|}
\hline Tvrdnja9 \\
\hline \multicolumn{1}{|c|}{ Valid } & 78 \\
Mean & 0 \\
Median & 2,6795 \\
Mode & 2,5000 \\
Std. Deviation & 2,00 \\
\hline
\end{tabular}

\begin{tabular}{|rl|r|r|r|r|}
\multicolumn{7}{c|}{ Tvrdnja9 } \\
\hline & & Frequency & Percent & $\begin{array}{c}\text { Valid } \\
\text { Percent }\end{array}$ & $\begin{array}{c}\text { Cumulative } \\
\text { Percent }\end{array}$ \\
\hline Valid &, 00 & 3 & 3,8 & 3,8 & 3,8 \\
& 1,00 & 15 & 19,2 & 19,2 & 23,1 \\
& 2,00 & 21 & 25,9 & 25,9 & 50,0 \\
3,00 & 15 & 19,2 & 19,2 & 69,2 \\
4,00 & 13 & 16,7 & 16,7 & 85,9 \\
& 5,00 & 11 & 14,1 & 14,1 & 100,0 \\
& Total & 78 & 100,0 & 100,0 & \\
\hline
\end{tabular}

Figure 9 shows the statistical analysis of the 9 th statement

Source: prepared by the author according to the conducted research

In the last question, respondents were asked to rate the subject "Algorithms and Programming". None of the respondents gave an unsatisfactory grade, 8 respondents $(10.25 \%)$ rated the subject as sufficient, 27 respondents (34.62\%) gave a good grade, 32 respondents (41.03\%) gave a very good grade, while 11 respondents $(14.10 \%)$ rated the subject with an excellent grade.

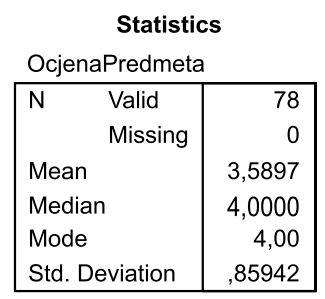

\begin{tabular}{|rr|r|r|r|r|}
\multicolumn{7}{|c|}{ OcjenaPredmeta } \\
\hline & & Frequency & Percent & $\begin{array}{c}\text { Valid } \\
\text { Percent }\end{array}$ & $\begin{array}{c}\text { Cumulative } \\
\text { Percent }\end{array}$ \\
\hline Valid & 2,00 & 8 & 10,3 & 10,3 & 10,3 \\
& 3,00 & 27 & 34,6 & 34,6 & 44,9 \\
& 4,00 & 32 & 41,0 & 41,0 & 85,9 \\
& 5,00 & 11 & 14,1 & 14,1 & 100,0 \\
& Total & 78 & 100,0 & 100,0 & \\
\hline
\end{tabular}

Figure 10 shows the statistical analysis of the 10 th statement

Source: prepared by the author according to the conducted research

In the last part of the questionnaire, the respondents were asked to solve a test that tested their programming skills. The test is structured according to the teaching units of the Vocational Curriculum for Acquiring the Qualification of Computer Technician from 2017. Respondents had to solve 11 tasks through the test. Each task had four answers offered, of which one or more answers were correct. Below are the test results according to each task. 
The first question tested knowledge of variable terminology. Out of the total number of respondents, 13 respondents answered correctly (16.67\%), while 65 respondents answered incorrectly (83.33\%). According to the distribution of answers by grades, 10 respondents $(45.45 \%)$ of the first grade answered the question correctly, while 12 respondents (54.54\%) answered incorrectly. In the second grade, 3 respondents (13.64\%) answered the question correctly, while the other 19 respondents (86.36\%) gave an incorrect answer. In the third and fourth grades, none of the respondents answered the given question correctly.

Distribution of answers by grades for the 1 st questions

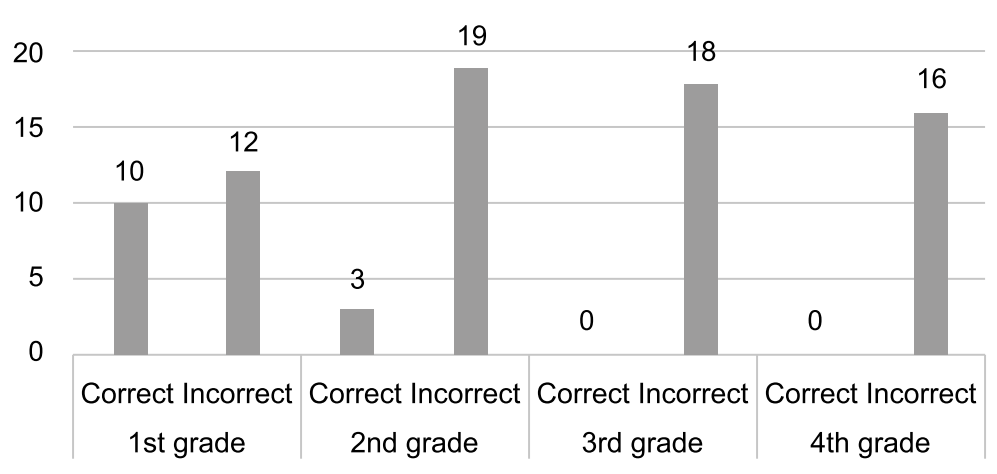

Graph 3 Distribution of answers by grades for the 1st question

Source: prepared by the author according to the conducted research

In the second question, respondents were asked to recognize what would be printed on the computer screen after the program code was executed. Out of the total number of respondents, 31 (39.74\%) gave the correct answer, while 47 respondents (60.26\%) answered the question incorrectly. To the second question in the first and second grade, 8 respondents (36.36\%) answered the question correctly, and 14 students (63.64\%) offered the wrong answer. In the third grade, 7 students (38.89\%) knew the answer, while 11 of them (38.89\%) answered the task incorrectly. In fourth grade, the ratio of correct and incorrect answers was equal.

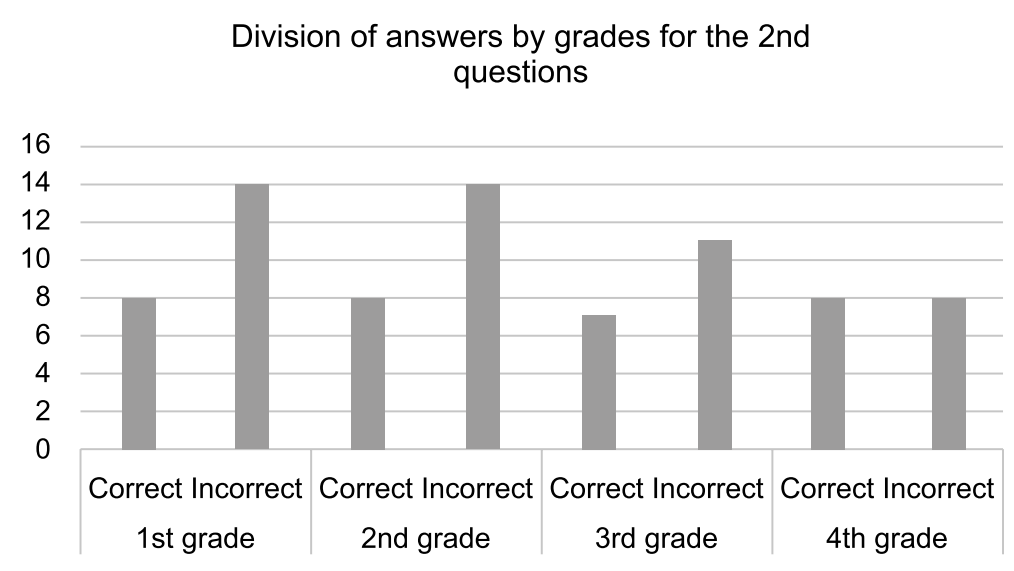

Graph 4 Division of answers by grades for the 2 nd question

Source: prepared by the author according to the conducted research

In the third question, the respondents had to identify which program code, out of the four offered, represents the default function. This task tested the knowledge of using branching commands. Out of a total of 78 respondents, 46 (58.97\%) answered correctly, while 32 
respondents (41.03\%) answered the question incorrectly. According to the distribution of answers by grades in the first grade, 15 students answered the question correctly (68.18\%), while 7 students (31.82\%) answered incorrectly. In the second grade, 10 respondents gave the correct answer (45.45\%), and 12 respondents gave the incorrect answer (54.55\%). 12 respondents $(66.67 \%)$ of the third grade answered the question correctly, while 6 respondents (33.33\%) gave an incorrect answer. In the fourth grade, 9 respondents $(56.25 \%)$ answered the question correctly, and 7 of them (43.75\%) had an incorrect answer.

Division of answers by grades for the 3rd questions

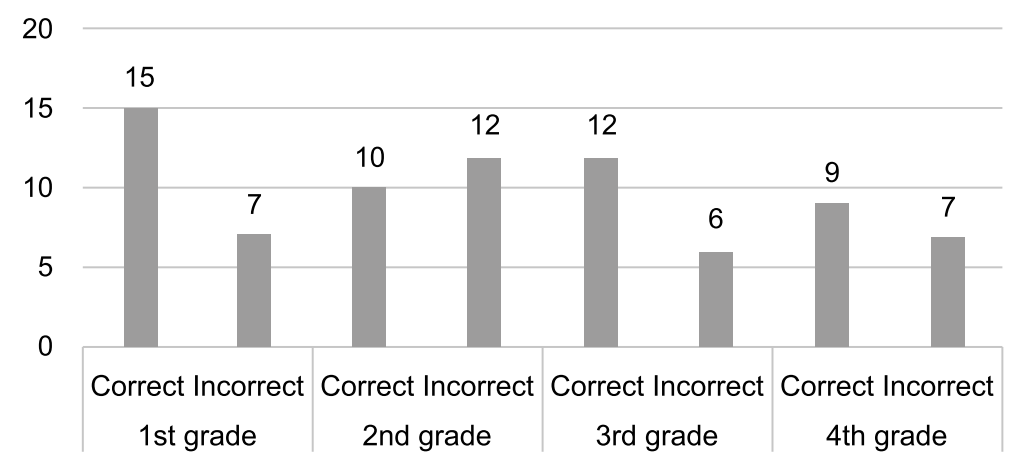

Graph 5 Division of answers by grades for the 3rd question

Source: prepared by the author according to the conducted research

The fourth question checked the respondents' understanding of the for loop. Of the total number of respondents, 55 (70.51\%) answered the question correctly, while 23 (29.49\%) gave the wrong answer. The distribution of answers by grades shows that in the first grade 19 students (86.36\%) knew the answer to the question, while 3 students (13.64\%) answered incorrectly. In the second grade, 13 students (59.09\%) answered correctly, and 9 of them (40.91\%) did not know the answer to the question. 15 students $(83.33 \%)$ in the third grade answered the fourth question correctly, while 3 students (16.67\%) answered incorrectly. In fourth grade, the ratio of students with correct and incorrect answers was equal.

Division of answers by grades for the 4th questions

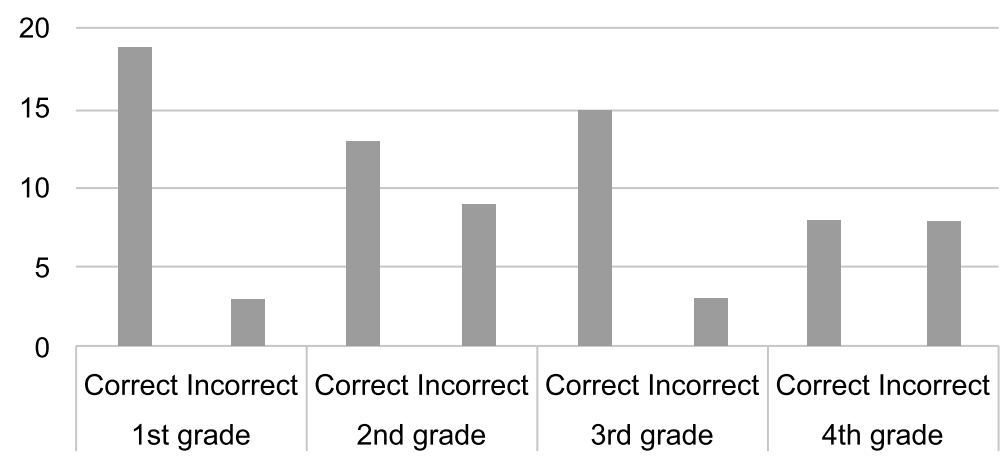

Graph 6 Division of answers by grades for the 4th question

Source: prepared by the author according to the conducted research

The fifth question checked the respondents' understanding of the program code in which the program loop and the branch command are used. Out of the total number of respondents, $43(55.13 \%)$ gave the correct answer, while 35 (44.87\%) answered the task incorrectly. To 
the fifth question, 15 students (68.18\%) of the first grade gave the correct answer, while 7 of them (31.82\%) answered incorrectly. In the second grade, there was an equal ratio of correct and incorrect answers. 7 students (38.89\%) of the third grade answered the fifth question correctly, and 11 of them (61.11\%) gave an incorrect answer. In the fourth grade, 10 students (62.50\%) knew the answer to the question, while 6 of them (37.50\%) answered incorrectly.

Division of answers by grades for the 5 th questions

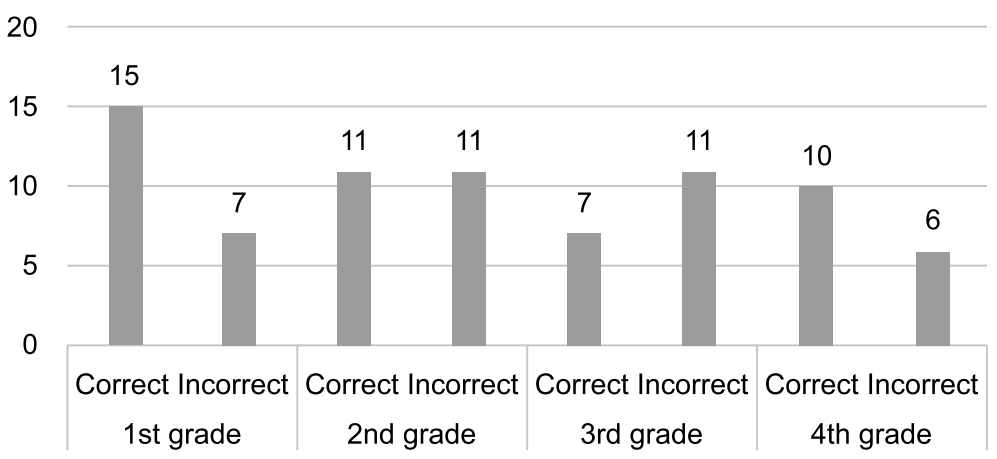

Graph 7 Division of answers by grades for the 5 th question

Source: prepared by the author according to the conducted research

In the sixth question, the respondents' understanding of the do-while program loop was checked. Of the total number of respondents, 31 (39.74\%) showed that they understood the do-while loop, while 47 (60.26\%) did not answer the question correctly. In the first grade, 6 students (27.27\%) gave the correct answer to the sixth question, while 16 students $(72.73 \%)$ answered incorrectly. In the second grade, the ratio of correct and incorrect answers was almost the same, ie 12 students (54.55\%) answered correctly, while 10 of them $(45.45 \%)$ gave the wrong answer. 8 students $(44.44 \%)$ in the third grade answered the question correctly, and 10 of them (55.56\%) answered incorrectly. In the fourth grade, only 5 students (31.25\%) gave the correct answer, while 11 students $(68.75 \%)$ gave the wrong answer.

Division of answers by grades for the 6th questions

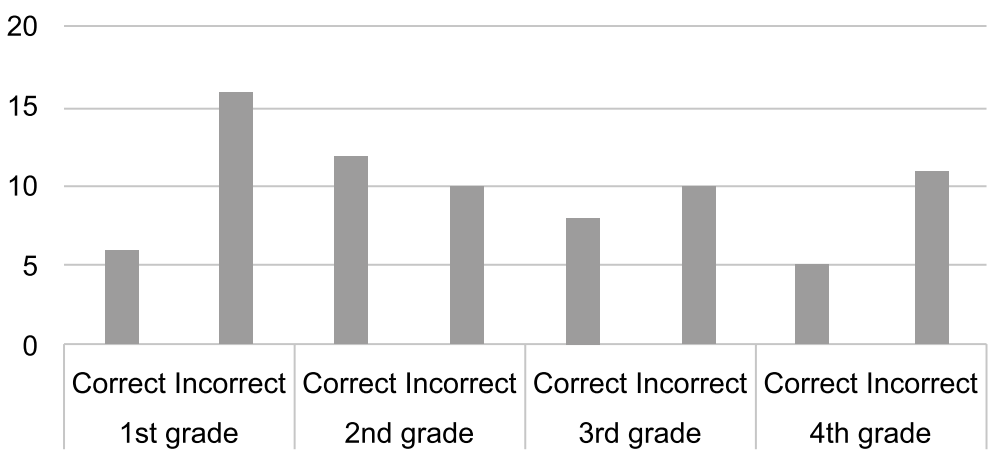

Graph 8 Division of answers by grades for the 6th question

Source: prepared by the author according to the conducted research

In the seventh question, students were tested on their knowledge and understanding of the nested program loop. Out of the total number of respondents, 14 (17.95\%) answered 
the question correctly, while $64(82.05 \%)$ answered the question incorrectly. In the first grade, only 1 student (4.55\%) answered the seventh question correctly, while 21 of them $(95.45 \%)$ answered incorrectly. In the second grade, 5 students $(22.73 \%)$ gave the correct answer, and 17 of them (77.27\%) answered incorrectly. 3 students $(16.67 \%)$ in the third grade answered the question correctly, while 15 of them (83.33\%) gave an incorrect answer. In the fourth grade, 5 students (31.25\%) knew the answer to the question, and 11 of them $(68.75 \%)$ answered incorrectly.

Division of answers by grades for the 7 th questions

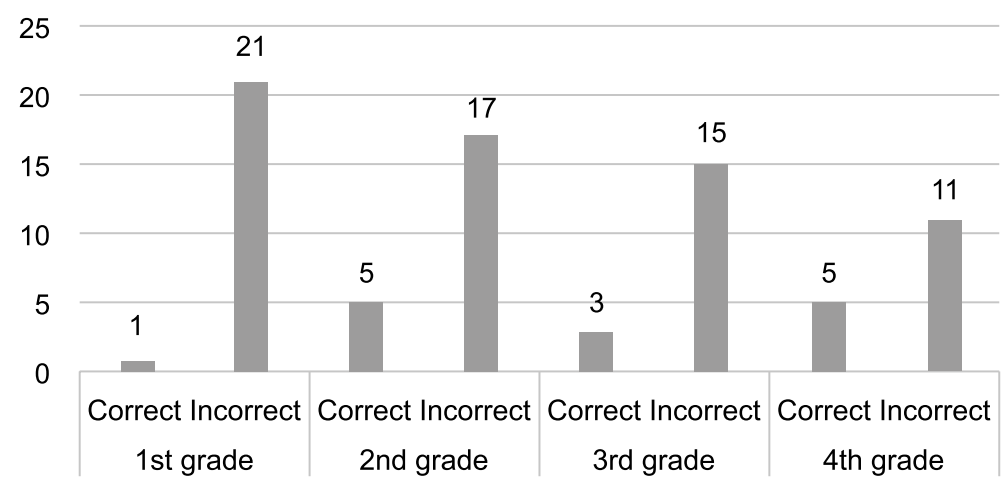

Graph 9 Division of answers by grades for the 7 th question

Source: prepared by the author according to the conducted research

In the eighth question, the students' understanding of the program structure of the field was checked. It is important to mention here that the first graders did not process this part of the material because it is being processed in the second grade of high school. Out of the total number of respondents, 16 (20.51\%) answered the question correctly, while 62 (79.49\%) gave an incorrect answer. The eighth question was answered correctly by 2 students (9.09\%), while the other 20 students (90.91\%) gave an incorrect answer. In the second grade, 10 students (45.45\%) answered correctly, and 12 of them incorrectly (54.55\%). 2 students $(11.11 \%)$ of the third grade gave the correct answer, while 16 of them (88.89\%) answered the task incorrectly. In the fourth grade, also only 2 students $(12.50 \%)$ answered correctly, and 14 students answered incorrectly (87.50\%).

Division of answers by grades for the 8th questions

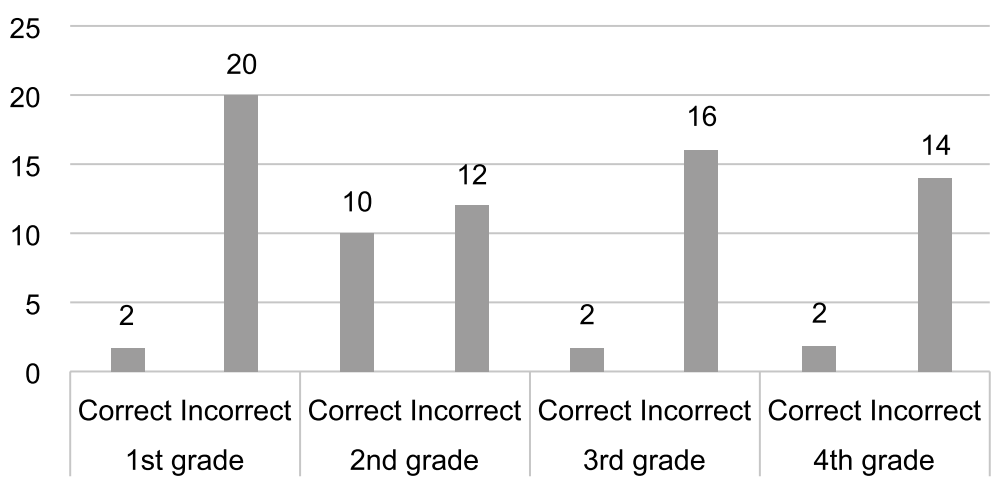

Graph 10 Division of answers by grades for the 8th question

Source: prepared by the author according to the conducted research 
The ninth question checked the respondents' knowledge of functions and recursion. Of the total number, none of the respondents answered the question correctly.

In the tenth question, knowledge of sorting algorithms was tested. Out of the total number of respondents, only 1 respondent (1.28\%), a second grade student, gave the correct answer, while all the others, 77 of them (98.72\%), answered the question incorrectly.

Division of answers by grades for the 10th questions

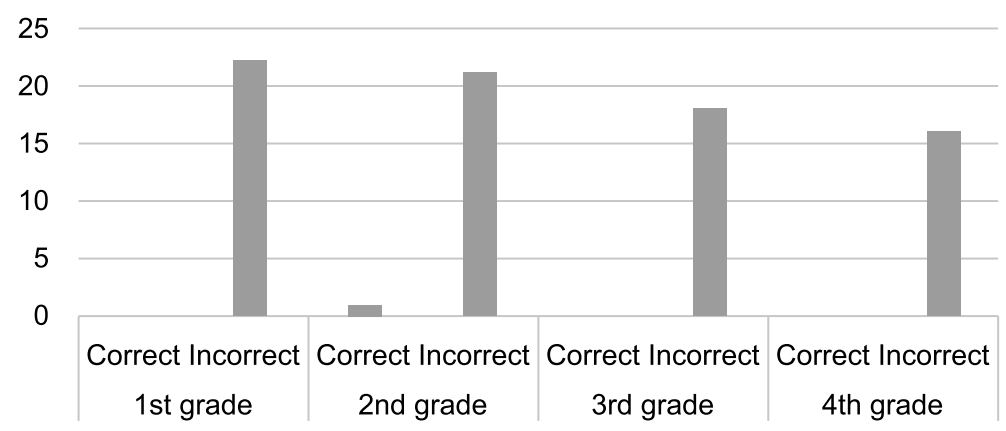

Graph 11 Division of answers by grades for the 10th question

Source: prepared by the author according to the conducted research

The last question checked the knowledge of the data structures, in this case the structure therefore. Out of the total number of respondents, 17 (21.79\%) answered correctly, while 61 respondents (78.21\%) answered incorrectly. In the first grade, 2 students gave the correct answer (9.09\%) and 20 students gave the incorrect answer (90.91\%). This result was expected given that they had not yet processed the said material. In the second grade, 10 students (45.45\%) answered the question correctly, while 12 (54.55\%) gave the wrong answer. Only 2 students (11.11\%) of the third grade answered the question correctly, and 16 $(88.89 \%)$ answered incorrectly. In the fourth grade, 3 students $(18.75 \%)$ knew the correct answer, while 13 students (81.25\%) answered the given question incorrectly.

Division of answers by grades for the 11 th questions

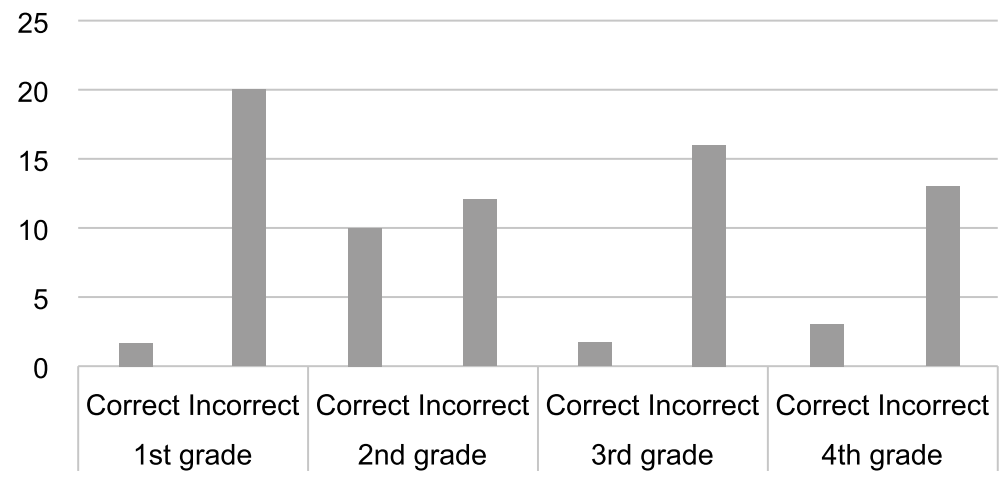

Graph 12 Division of answers by grades for the 11th question

Source: prepared by the author according to the conducted research 


\section{RESULTS AND DISCUSSION}

H0: Developed programming skills of High School students, majoring in Computer Science Technician are not in line with the set outcomes of the Vocational Curriculum for acquiring the qualification of Computer Science Technician for the subject "Algorithms and Programming". The third part of the questionnaire "Assessment of programming skills (c ++ programming language)" based its questions on how to cover the basic educational categories of programming skills in accordance with the Vocational Curriculum for the acquisition of the qualification of computer technician. Therefore, for the processing of this hypothesis, the results of all students achieved in the third part of the questionnaire were taken into account as input parameters. In order to be able to assess whether the students have acquired sufficient knowledge in the subject "Algorithms and Programming", the results were processed separately for each class. For the students to pass the questionnaire, it was necessary to achieve 6 or more points out of a total of 11 .

Total pass rate by grades

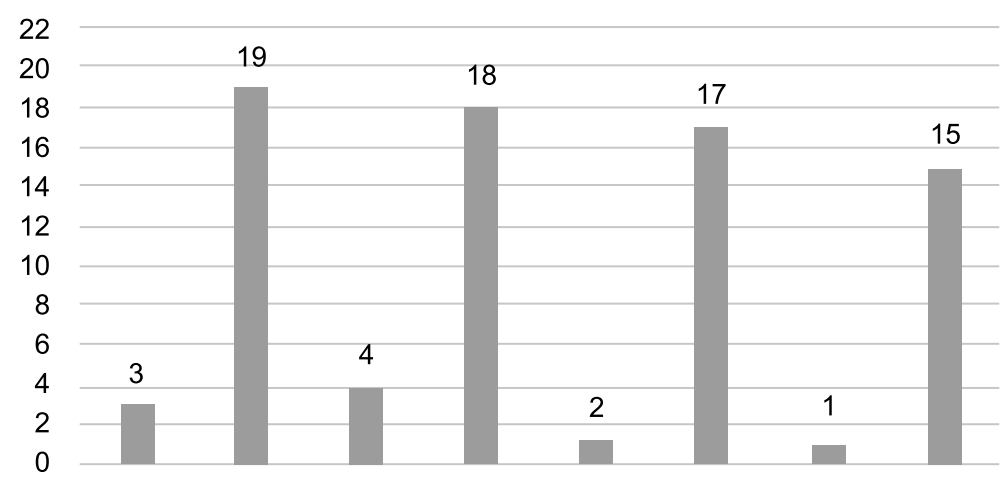

Graph 13 Total pass rate by grades

Source: prepared by the author according to the conducted research

Graph 13 shows that in the first grade only 3 students (13.63\%) achieved passing, i.e. that 19 students $(86.37 \%)$ did not pass. In the second grade, 4 students $(18.18 \%)$ achieved transit, i.e. 18 students (81.82\%) did not pass. In the third grade, only 1 student (5.55\%) achieved a pass rate, while 17 of them (94.45\%) did not achieve a pass rate. In the fourth grade, only 1 student (6.25\%) achieved a pass rate, while $15(93.75 \%)$ did not pass it. 


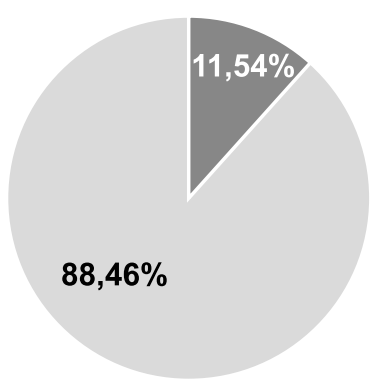

Graph 14 Total passability

Source: prepared by the author according to the conducted research

Graph 14 shows that the total student pass rate is $11.54 \%$ (9 students), or $88.46 \%$ (69 students). Accordingly, it can be said that the development of programming skills of high school students, the direction of computer technician is not in line with the set outcomes for the subject "Algorithms and Programming" of the Vocational Curriculum for the qualification of computer technician. The reason for these results certainly lies in the fact that students do not have properly prescribed or binding literature for learning and practicing programming. In addition, the working conditions of students and teachers are not appropriate (lack of necessary equipment, outdated technology, etc.) and sometimes the teaching is reduced to improvisation of teachers, their personal attitude to the importance of certain teaching materials and individual commitment to the curriculum. Such conditions certainly affect the commitment of the students themselves. Improving conditions in vocational schools can certainly lead to greater motivation among students, and thus to better results.

H1: There is no significant difference in programming knowledge and skills between lower (first, second, third grade) students and fourth grade high school students.

Auxiliary hypothesis $\mathrm{H} 1$ was tested using the chi-square test. The first input parameter is the sum of correct and incorrect answers for first, second and third grade students, and the second parameter is the sum of correct and incorrect answers of fourth grade students from the third part of the questionnaire "Assessment of programming skills (c ++ programming language"). Students were able to achieve one point for each correct answer, which together, first, second and third grade students could achieve 682 points, while fourth grade students could achieve a total of 176 points. According to statistical tables, the parameter according to which the decision was made was 3.841 ( $\mathrm{p}<.05)$, which means that if $\mathrm{X}^{2}$ (chi-square) is greater than 3.841, the auxiliary hypothesis is rejected. The obtained test results are shown in Figure 11.

\begin{tabular}{|l|l|l|l|}
\hline \multicolumn{4}{|c|}{ Results } \\
\hline & $\mathbf{1 - 2 - 3}$ class & 4 class & Row Totals \\
\hline Correct answers & $217(212.23)[0.11]$ & $50(54.77)[0.42]$ & 267 \\
\hline Incorrect answers & $465(469.77)[0.05]$ & $126(121.23)[0.19]$ & 591 \\
\hline Column Totals & $\mathbf{6 8 2}$ & $\mathbf{1 7 6}$ & $\mathbf{8 5 8}$ (Grand Total) \\
\hline
\end{tabular}

The chi-square statistic is 0.7585 . The $p$-value is .383794 . The result is not siginificant at $p<.05$.

Figure 11 shows the result of the Hi-square test for $\mathrm{H} 1$

Source: prepared by the author according to the conducted research 
The obtained result $\mathrm{X}^{2}=0.7585$ (value less than 3.841) indicated that there is no significant difference in programming knowledge and skills between lower (first, second, third grade) students and fourth grade high school students which means that hypothesis H1 is accepted.

H2: Students with poorer general averages have less developed programming skills.

Spearman's rho correlation test was used for the auxiliary hypothesis H2, which states that students with poorer general averages have less developed programming skills. The test was performed by using the ranked results for the general average of students from the first part of the questionnaire "General data on the respondent" and the ranked results of the sum of correct answers from the third part of the questionnaire "Assessment of programming skills $(\mathrm{C}++$ programming language $)$ ) "For each respondent. The general average of students was taken as a variable that was directly ranked depending on its value (1-5), while the ranked score of correct answers was based on the sum of correct answers, i.e. the maximum number that the respondent could achieve was 11 points and minimum 0 points . In the test, the data of all 78 subjects were taken and the following results were obtained:

X Values
\begin{tabular}{|l|}
\hline 59.5 \\
59.5 \\
22.5 \\
59.5 \\
22.5 \\
22.5 \\
59.5 \\
59.5 \\
22.5 \\
59.5 \\
59.5 \\
59.5 \\
59.5 \\
59.5 \\
59.5 \\
59.5 \\
59.5 \\
59.5 \\
22.5 \\
59.5 \\
59.5 \\
\hline
\end{tabular}

Y Values
\begin{tabular}{|l|}
\hline 32.5 \\
65.5 \\
65.5 \\
13.5 \\
32.5 \\
32.5 \\
32.5 \\
54 \\
54 \\
32.5 \\
32.5 \\
13.5 \\
13.5 \\
73 \\
77.5 \\
65.5 \\
32.5 \\
5 \\
13.5 \\
73 \\
32.5 \\
\hline
\end{tabular}

\begin{tabular}{|c|c|}
\hline$X_{R o}$ & $X_{R a}-M_{x}$ \\
\hline $59.50 \wedge$ & $20.00=$ \\
\hline 59.50 & 20.00 \\
\hline 22.50 & -17.60 \\
\hline 59.50 & 20.60 \\
\hline 22.50 & -17.00 \\
\hline 22.50 & -17.00 \\
\hline 59.50 & 20.00 \\
\hline 59.50 & 20.00 \\
\hline 22.50 & -17.00 \\
\hline 59.50 & 20.00 \\
\hline 59.50 & 20.60 \\
\hline 59.50 & 20.60 \\
\hline 59.50 & 20.60 \\
\hline 59.50 & 20.00 \\
\hline 59.50 & 20.00 \\
\hline 59.50 & 20.60 \\
\hline 59.50 & 20.00 \\
\hline 59.50 & $20 . \theta 0$ \\
\hline 22.50 & -17.60 \\
\hline 59.50 & 20.00 \\
\hline $59.50^{\circ}$ & $20.60^{-}$ \\
\hline 22.50 & -17.00 \\
\hline
\end{tabular}

\begin{tabular}{|c|c|}
\hline$Y_{R a}$ & $Y_{R a}-M_{y}$ \\
\hline $32.50 \AA$ & $-7.60 \wedge$ \\
\hline 65.50 & 26.00 \\
\hline 65.50 & 26.00 \\
\hline 13.50 & -26.00 \\
\hline 32.50 & -7.00 \\
\hline 32.50 & -7.60 \\
\hline 32.50 & -7.00 \\
\hline 54.60 & 14.50 \\
\hline 54.00 & 14.50 \\
\hline 32.50 & -7.00 \\
\hline 32.50 & -7.60 \\
\hline 13.50 & -26.00 \\
\hline 13.50 & -26.00 \\
\hline 73.00 & 33.50 \\
\hline 77.50 & 38.00 \\
\hline 65.50 & 26.60 \\
\hline 32.50 & -7.60 \\
\hline 5.60 & -34.50 \\
\hline 13.50 & -26.60 \\
\hline 73.00 & 33.50 \\
\hline $32.50^{\circ}$ & $-7.80^{\circ}$ \\
\hline 32.50 & -7.60 \\
\hline
\end{tabular}

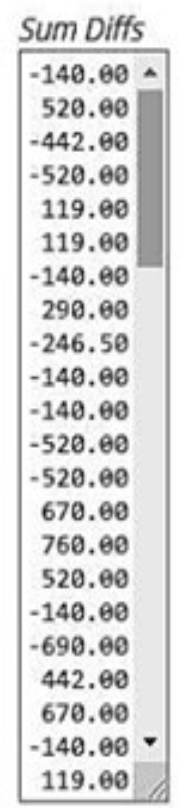

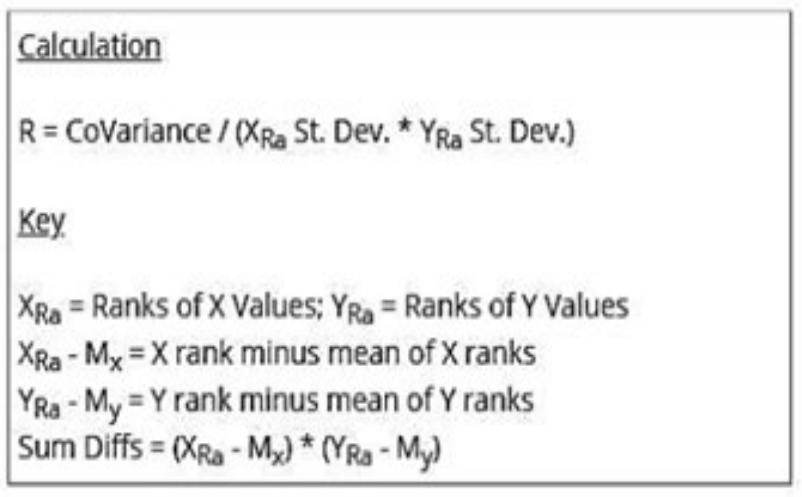

$r_{s}=0.11899, p(2$-tailed $)=0.29943$.

\section{Result Details \\ X Ranks \\ Mean: 39.5 \\ Standard Dev: 20.04 \\ YRanks \\ Mean: 39.5 \\ Standard Dev: 22 \\ Combined \\ Covariance $=4039.5 / 77=52.46$ \\ $R=52.46 /(20.04 * 22)=0.119$}

Figure 12 shows the results of Spearman's rho correlation test for hypothesis $\mathrm{H} 2$

Source: prepared by the author according to the conducted research 
By checking the significance of the results, the obtained $r$ / rho value ( $r s=0.11899, p$ $<0.05$ ) is less than the reference value ( $r s=0.223, \mathrm{p}<0.05$ ) according to the statistical table for critical Spearman's rho values, which means that no significant correlation was found between students with a poorer general average have less developed programming skills, so there are no arguments to confirm the hypothesis and reject it. The results of this test can be confirmed by the fact that the general average of students does not depend directly on one subject in which students may be more or less interested, given that students majoring in computer science have other general subjects that affect the average. evaluation.

H3: Students who have a negative attitude about the subject "Algorithms and Programming" have less developed programming skills.

Spearman's rho correlation test was also used for the auxiliary hypothesis H3, which states that students who have a negative attitude towards the subject "Algorithms and Programming" have less developed programming skills. During the test, the results obtained for the general position on the case were ranked by adding up the total score on the attitudes of each respondent. If the respondent answered all the questions in the second part of the questionnaire "I completely agree", then he awarded the maximum number of points (55 points) and stated that he has an extremely positive attitude about the subject. Analogously, if the respondent answered all the questions "I completely disagree", then he awarded the case a minimum number of points (11 points) and stated that he has an extremely negative attitude. The second parameter for conducting this test was the sum of correct answers in the third part of the questionnaire "Assessment of programming skills ( $\mathrm{C}++$ programming language)" for each respondent. The respondent could achieve a maximum of 11 points and a minimum of 0 points. These results are also ranked. In the test, the data of all 78 subjects were taken and the following results were obtained: 
differences in the knowledge of lower and final grade high school students, which can be justified by the fact that students have the subject "Algorithms and Programming" in the first two grades on programming.

In conclusion, the research indicated that there are a number of omissions and shortcomings in teaching programming and that it is necessary to introduce new methods and forms of working with students. Develop effective teaching models and conduct continuous research to reach new insights and conclusions.

\section{REFERENCES}

Aureliano, V. C. O. (2013). A methodology for teaching programming for beginners. ICER '13: Proceedings of the ninth annual international ACM conference on International computing education research, 169-170. Retrieved from https://doi.org/10.1145/2493394.2493417

Grandell, L., Peltomäki, M., Back, J., Salakoski, T. (2006). Why Complicate Things? Introducing Programming in High School Using Python. Turku Centre for Computer Science. Retrieved from https://www.researchgate. net/publication/31596786_Why_Complicate_Things_Introducing_Programming_in_High_School_Using_ Python

Gülbahar, Y., Kalelioğlu, F. (2014). The Effects of Teaching Programming via Scratch on Problem Solving Skills: A Discussion from Learners' Perspective. Informatics in Education - An International Journal, 1(2014), 33-50. Retrieved from https://www.ceeol.com/search/article-detail?id=123695

Kiss, G. (2013). Teaching Programming in the Higher Education not for Engineering Students. Procedia Social and Behavioral Sciences, 103 ( 2013 ), 922 - 927.

Konidari, E., Louridas, P. (2010). When Students Are Not Programmers. ACM Inroads, 1 (2010), 55-60.

Major, L., Kyriacou, T., Brereton, P. (2011). Experiences of Prospective High School Teachers Using a Programming Teaching Tool. Koli Calling International Conference on Computing Education Research, 126131.

Saeli, M., Perrenet, J., Jochems, W.M.G., Zwaneveld, B. (2011). Teaching Programming in Secondary School: A Pedagogical Content Knowledge Perspective. . Informatics in Education - An International Journal, 1(2011), 73-88. Retrieved from https://www.ceeol.com/search/article-detail?id=69618

Schulte, C. (2013). Reflections on the role of Programming in Primary and Secondary Computing Education. WiPSE '13: Proceedings of the 8th Workshop in Primary and Secondary Computing Education, 17-24. https://doi.org/10.1145/2532748.2532754

Tepgeç, M., Demiraslan Çevik Y. (2018). Comparison of Three Instructional Strategies in Teaching Programming: Restudying Material, Testing and Worked Example. Journal of Learning and Teaching in Digital Age, 3(2), 42-50. 